\title{
NOCIONES DE LO COMÚN: COMUNIDAD Y ACCIONES POLÍTICO-COMUNICATIVAS
}

\section{Ideas about the Common: Community and Political-Communicative Actions}

\author{
Delmar Ulises Méndez-Gómez*
}

DOI: http://dx.doi.org/10.29043/liminar.v19i1.819

Reseña de Prácticas comunicativas y prefiguraciones políticas en tiempos inciertos, de Amaranta Cornejo Hernández (coord.). Tuxtla Gutiérrez, Chiapas: Universidad de Ciencias y Artes de Chiapas, 2018.

P rácticas comunicativas y prefiguraciones políticas en tiempos inciertos, coordinado por Amaranta Cornejo Hernández, es un libro no solo emergente, sino políticamente necesario, pues consigue reunir distintas miradas, posturas, abordajes y experiencias que comparten las autoras y los autores en cada uno de los ensayos, escritos con una visión crítica y propositiva de las realidades adversas y violentas en México y Honduras. Y no solo las estudian, sino que son parte de ellas. Las contribuciones, insertas en el campo de la comunicación, el género, el feminismo y los estudios decoloniales, logran una imbricación entre teoría, análisis académico, práctica, activismo y movimiento social, y hacen del libro un "sentipensar colectivo" que expone los modos de organización y participación que distintos actores llevan a cabo en estos tiempos en que se hace fundamental la búsqueda de nuevos horizontes.

Este libro se publica, además, en un momento oportuno, pues varios de los estudios de caso trastocan cada dimensión de nuestro presente y visibilizan los efectos que el narcotráfico, la violencia, la desaparición forzada,

\footnotetext{
* Delmar Ulises Méndez Gómez. Doctorante en Ciencias Antropológicas en la Universidad Autónoma Metropolitana-Itztapalapa, México. Integrante del Observatorio de las Democracias: Sur de México y Centroamérica (ODEMCA), del Centro de Estudios Superiores de México y Centroamérica de la Universidad de Ciencias y Artes de Chiapas (CESMECA-UNICACH). Temas de especialización: comunicación y
}

el extractivismo, la desigualdad, la discriminación, el racismo y la exclusión social provocan, lo que a su vez genera nuevas formas de resistencia y lucha mediante la conformación de colectivos, organizaciones, grupos de trabajo y movimientos que buscan protestar, contrarrestar y eliminar dichos efectos por medio de la incidencia política, cultural y artística. Se une a ello la resignificación de los medios de comunicación, como la internet, y del cuerpo no solo como materia, sino como territorio, arte y expresión de las emociones, los sentimientos, la corporalidad y la performatividad.

La prefiguración, más allá de ser un concepto, es un elemento medular que orienta la reflexión general, al fundarse no solo en acciones que surgen ante lo contingente como una respuesta contrahegemónica o antisistema, sino en las formas cotidianas de acción colectiva, de hacer comunidad, de crear redes de apoyo y acompañamiento, de socializar la experiencia y de potenciar las voces de quienes exigen justicia y no han encontrado los medios para enunciarse. Se trata de dislocar y eliminar todas las formas de violencia, de opresión y explotación. Así surge el sentido político de

cultura; sociología de la memoria. Correo electrónico: delmarmego@ gmail.com. ORCID: https://orcid.org/0000-0001-7582-7748

Recibida: 19 de marzo de 2019.

Aprobada: 15 de septiembre de 2020. 
la prefiguración: la búsqueda horizontal de reorganización de la vida a partir de las nociones de lo común. Esto se logra comprender en los nueve ensayos presentados en los tres apartados generales: "Las prefiguraciones en/ de/desde Internet", "Los discursos y las prácticas desde la corporalidad" y "Prefiguraciones desde lo común y en tiempos inciertos".

En el primero de ellos se traza una reflexión en común, que internet es un medio y un espacio en disputa. Domingo Lechón Gómez, integrante del colectivo Sursiendo, analiza la posibilidad de construir una internet biodiversa y responsable, lejos de la lógica mercantil que la ha caracterizado en las últimas décadas. El autor menciona que más de la mitad de la población mundial es usuaria de internet y, apoyándose de los planteamientos de Manuel Castells y Enrique Dans, reflexiona que la internet, además de ser significada como un medio digital, es una red de información global, un dispositivo y un espacio que puede tener una doble función; por un lado, generar dependencia, control y reproducción de las lógicas de poder y económicas, como en el caso de las operaciones de vigilancia (Hermann, 2013) y, por el otro, crear alternativas de resistencia, de denuncia, de iniciativa y habilitación de hardware libre. La internet es una herramienta que se ha integrado a los movimientos sociales, que no solo se mueven en el espacio físico-público, sino en el virtual-digital; en este último caso son considerados "movimientos en red", y entre ellos destacan las Primaveras Árabes, el movimiento \#YoSoyl32 en México y Passe Livre en Brasil. Uno de los esbozos más sugerentes refiere a la aseveración de que en la internet existe activismo tecnológico —es decir, hacktivistas - que "se concibe como un tipo de participación política no convencional que pretende a través de prácticas contra-informativas y subversivas incidir en el orden social" (p. 27). Ellas pueden aportar a la construcción de una "comunalidad y biodiversidad digital" que permita a todos los usuarios acceder a la internet de manera libre, en la que se pueda descargar, compartir, distribuir, imprimir y ver distintos contenidos con propósitos legales; volver a habitar la internet de manera "libre, segura, inclusiva, social y heterogénea", distanciada de la lógica mercantil, empresarial y contro- lada, que cada vez más está "en manos de corporaciones extractivas y gobiernos vigilantes” (p. 34).

Por su parte, Lisseth Pérez Manríquez escribe sobre la creciente participación de mujeres ciberfeministas en México, quienes han resignificado la internet como un medio en el cual pueden llevar la lucha contra las prácticas patriarcales que generan desigualdad y dominación, pues la red "es construida desde el pensamiento capitalista y patriarcal [...] las mujeres, al integrarse a ese espacio, siguen vulnerables ante los mismos procesos sociales de exclusión y violencia a los que están expuestas en el espacio offline" (p. 4l). La autora esboza un análisis sobre el ciberfeminismo - la vinculación del feminismo e internet - y el trabajo de las mujeres con la tecnología. En primera instancia, ofrece datos históricos sobre las mujeres en la historia de internet, quienes, aun cuando la historia oficial no las reconoce, tuvieron una preponderante intervención en el desarrollo de la red. En segundo lugar, esboza la historia del ciberfeminismo en el mundo a partir de experiencias concretas y las conecta con el contexto mexicano, como con la organización Centro de Investigación y Capacitación de la Mujer (CICAM) y la página web Ciberfeministas, de Cindy Flores. Ello desvela el auge de experiencias que crean "formas de colaboración, creación de contenidos con posturas feministas, que [enriquece] el debate sociotécnico y político alrededor de esta red" (p. 44). La participación de las mujeres en las estructuras del desarrollo de la internet incide en la resignificación de las subjetividades, pues hace que se cuestionen su lugar como mujeres en los espacios que habitan, tanto en el espacio online como en el offline. Apelan a la construcción de una tecnología inclusiva que trascienda la lógica dicotómica de la oposición jerárquica, la cual preestablece el ordenamiento de los cuerpos y los espacios: hombre/mujer, razón/emoción, tangible/intangible, tecnología/naturaleza, offline/online.

El segundo apartado "Los discursos y las prácticas desde la corporalidad", consta de un eje principal: la reflexión del cuerpo como espacio de enunciación y protesta. El cuerpo es el mensaje, es la configuración política de la protesta y la lucha. En este tenor, Miriam Bautista Arias escribe sobre la experiencia de 
mujeres que viven en contextos con altos índices de violencia, recuperando particularmente la situación en los estados de Tamaulipas, Nuevo León y Morelos. La autora se plantea dos preguntas generales: cómo la subjetividad femenina es modelada por la violencia y cómo las mujeres rehabitan la cotidianidad desde la condición de violencia. Su marco histórico se sitúa en la "guerra contra el narcotráfico" iniciada por Felipe Calderón (2006-2012), al enviar a las fuerzas armadas a las calles para realizar tareas de "seguridad", es decir, con la militarización del espacio público. Bautista Arias, apoyándose en los métodos del análisis del discurso, reflexiona sobre la configuración de la vida de las mujeres que se hallan en contextos rebasados por la inseguridad, al punto de convertirlas "en algo desechable" (p. 75). Los testimonios reflejan los cambios que la violencia ha ocasionado en la cotidianidad de las mujeres, el desprendimiento social con las amistades, la familia, los espacios de convivencia y el trabajo. Se comparten experiencias traumáticas y dolorosas, pero también de mujeres que buscan justicia y que trabajan sobre sí mismas para rehabitar su cotidianidad.

Los casos compartidos conectan con muchos otros que todavía permanecen sin ser escuchados, como sucede con las mujeres que viven en condición de calle, de las que Mónica Orozco Torres escribe para devolver la mirada sobre los cuerpos que parecen no importar a nadie, que yacen en lo invisible, lo impronunciable, lo rechazado y lo abyecto. "Estos cuerpos, llenos de significación, se convierten en el principal elemento de rechazo, maltrato y exclusión por parte de otros hacia estas mujeres [...] evidencia la situación de precariedad en que viven; sin embargo, algunas, por momentos, pueden desprenderse de este cuerpo estigmatizado" (p. 93). Orozco Torres parte del análisis de que esas mujeres habitan un cuerpo en constante tensión y reconfiguración. Ofrece testimonios que visibilizan las razones y problemas que llevan a las mujeres a habitar en la calle, y escribe sobre sus sentimientos, sus espacios de intimidad, de trabajo y de recreación. Algunas relatan su papel de madres pues, aunque nadie se lo pregunte, ellas también tienen el deseo de experimentar la maternidad. Asimismo, la autora señala el estigma y el constante rechazo que viven, "pareciera que la cercanía con cuerpos como estos [...] fuese contagiosa y por ello hay que mantenerse al margen, evitar el contacto físico y hasta visual" (p. 108).

Andrea de la Hidalga Ríos continúa sobre el mismo eje reflexivo y escribe sobre las experiencias de mujeres trabajadoras domésticas en Puebla. Desarrolla un análisis sobre la desigualdad, el racismo, la discriminación y las relaciones de poder entre el binomio empleadora/ trabajadora, que se reproducen no solo al interior de los hogares, sino en otros espacios públicos, y que refuerzan el imaginario "desde un determinado grupo social respecto al 'otro' que es considerado diferente tanto racial, como culturalmente" (p. 114). Toma como unidades de reflexión los espacios habitables, la importancia atribuida al color de la piel y a cierto fenotipo para reforzar la identidad y la estigmatización del cuerpo, y su relación con la identidad y el imaginario. De la Hidalga Ríos logra exponer, apoyándose en varios testimonios, las diferencias y distancias que se establecen en los espacios de la casa, los lugares para la familia de "la jefa" y los permitidos para "la muchacha", los momentos de recreación, los utensilios que las empleadas pueden usar y la comida que consumen. Asimismo, visibiliza la huella colonial que se reproduce al identificar ciertos patrones y conductas como la superioridad que asume la empleadora, que incide en la construcción y legitimación de un imaginario social sobre las trabajadoras, y que refuerza las jerarquías de clase y de "raza", perpetuando "una cultura de dominación" (p. 128).

El tercer apartado, "Prefiguraciones desde lo común y en tiempos inciertos", también mantiene una unidad temática: la acción y participación colectiva. Cristina Híjar González esboza una reflexión sobre las acciones político-estéticas colectivas "que contribuyen al entendimiento de lo político en la protesta" (p. 136), sobre uno de los acontecimientos más trágicos de la historia reciente de México y que continúa sin alcanzar justicia: la desaparición forzada de 43 estudiantes de la Escuela Normal Rural Raúl Isidro Burgos en Ayotzinapa, Guerrero. Híjar González analiza varios elementos simbólicos que se producen durante la protesta. Por un lado, las consignas: "Fue el Estado" y "Ni una sola 
lucha aislada más", que "apuntan a la responsabilidad compartida en un mundo común" (p. 137); iPorque vivos se los llevaron, vivos los queremos!, consigna que no refiere únicamente a los estudiantes desaparecidos, sino a todas las víctimas de la violencia sistémica, que se expresa simbólicamente en el cambio del numeral del 43 $a+43$. Por el otro, muestra los retratos dibujados de los desaparecidos y la performatividad de los cuerpos durante la protesta, es decir, formas de lucha poéticas que permiten movilizar conciencia, acciones, pensamientos y sentidos de pertenencia. Estas modalidades de lucha hacen de las marchas "una acción colectiva afirmativa del Nosotros" (p. 144) que apela a lo político: asumir que la vida es un problema en común, una responsabilidad de todos. La protesta social-estética fortalece el sentido político colectivo e interpela el discurso hegemónico oficial que el Estado, en tiempos del Partido Revolucionario Institucional (PRI), intentó imponer con su versión de "la verdad histórica".

Ello se vincula con lo que Reyna Sánchez Estévez escribe, al recuperar el trabajo de colectivos y organizaciones que luchan contra los megaproyectos neoliberales, legitimados por las instancias gubernamentales, que despojan, privatizan y destruyen el medio ambiente y el territorio donde habitan las comunidades. El texto, que es también un documento de denuncia, visibiliza el actuar del Estado mexicano, que transforma "las leyes del país [para favorecer el saqueo] y legalizar el despojo" (p. 158). Sánchez Estévez retoma algunos casos, entre los tantos que existen, para exponer el modo en que las políticas extractivas y megaproyectos afectan a varias comunidades; destaca un caso del Estado de México, donde pobladores mantienen una lucha contra el proyecto carretero Toluca-Naucalpan, así como los casos del pueblo de Xoco y de las colonias Santa Cruz Atoyac y General Anaya en la Ciudad de México, que, al resultar con graves afectaciones tras el terremoto ocurrido en septiembre de 2017, luchan contra los proyectos inmobiliarios. El desastre ocasionado por el fenómeno natural también se vincula con la irresponsabilidad, la impunidad y la corrupción con la que se otorgan los permisos en lugares con alto riesgo de colapso, que la autora visibiliza a partir de ocho casos actuales.
El texto de Sánchez Estévez mantiene relación con el de Luz Aída Ruiz Martínez quien, a modo anecdótico y dialógico, escribe sobre la experiencia de lucha de la propia autora y de las compañeras integrantes del Consejo Cívico de Organizaciones Populares Indígenas de Honduras (COPINH), fundado en abril de 2014 por integrantes del pueblo originario lenca, ubicado en el occidente de este país. Desde su fundación han resistido trabajando por la defensa de la tierra y del medio ambiente, al hallarse en una zona rica en recursos naturales que es de interés de varios proyectos energéticos que intentan instalarse en el territorio. Ruiz Martínez recupera la labor de la Iglesia católica de Honduras que, por medio del programa Celebradores de la Palabra y del Club de Amas de Casa, contribuyó para que varias mujeres accedieran a oportunidades educativas y organizativas inaccesibles en la década de los sesenta, acontecimiento que llevó a varias a integrarse al COPINH. Juntas han luchado por el reconocimiento de los derechos sociales, económicos, políticos y culturales del pueblo lenca y han realizado demandas en contra de la violencia sexual y de género, hasta lograr el reconocimiento de nuevas leyes que protegen a las mujeres. Asimismo, comparten las acciones comunicativas colectivas que han llevado a cabo mediante el uso de la radio, con la cual han difundido contenidos para concientizar a los pueblos ejerciendo su derecho a la comunicación.

La lucha de las mujeres del COPINH en materia de derechos humanos y contra la violencia mantiene un correlato con las experiencias de vida de aquellas que participan en la Casa de la Mujer Indígena (CAMI) en Tlaola, Puebla, sobre las que escribe Juan Vicente López Rodríguez. Este autor, a partir de las teorías feministas decoloniales y los estudios en comunicación, analiza el discurso sobre las desigualdades y la violencia de género, realizando una distinción entre "el género como una estructura binaria y como parte de una dualidad" (p. 183). Esboza una reflexión sobre el debate en torno a la (in)existencia del género como desigualdad en el mundo precolonial, y para ello recupera los planteamientos propuestos por Segato (2016), Paredes (2013) y Marcos (2014), con los que el autor asevera que "el 
género existe, pero de una forma distinta que en la modernidad; cuando ésta se aproxima al género del mundo-aldea lo 'innova' peligrosamente" (p. 188). Los relatos de las mujeres permiten al autor repensar las teorías feministas, al considerar la condición cultural para entender cómo se construyen y reproducen las desigualdades y el ejercicio del poder.

En suma, el libro encuentra su base, su fundamento, a partir de una polifonía de voces y testimonios que nos permiten comprender y experimentar los casos que se exponen, con una cercanía que solo se logra cuando se hallan insertas la subjetividad y las emociones de quienes escriben. Esto es, sin duda, la característica de una práctica comunicativa Otra y la prefiguración política que se busca: ser y sentirse parte del acontecimiento, de la reflexión. Asimismo, vale la pena destacar el lugar del "tiempo incierto", que no se concibe como algo que se desconoce o que es difícil de predecir, sino que, por el contrario, se trata de intervenir ante la emergencia de los escenarios actuales, de las realidades adversas, que inciden directamente en lo que está por suceder. En este sentido, el "tiempo incierto" es un punto de arranque que abre todas las posibilidades de acción que se gestan en diferentes regiones, como se deja ver en los nueve ensayos reunidos en este libro.

Los textos, en su mayoría, son resultado de las tesis de grado de varios de los autores y autoras, como en los casos de Domingo Lechón, Lisseth Mariana Pérez,
Miriam Bautista Arias, Andrea de la Hidalga, Cristina Hijar, Juan Vicente López y Luz Aída Ruiz. Ello da cuenta del interés y el compromiso no solo académico, sino político, que cada uno de ellos y ellas asume en su formación y práctica cotidiana. El libro es un texto de imprescindible lectura, pues permite comprender nuestra realidad social, formular interrogantes e impulsar acciones colectivas en estos "tiempos inciertos" que están justo aquí, frente a nosotras y nosotros.

\section{Referencias}

Cornejo Hernández, Amaranta (coord.) (2018). Prácticas comunicativas y prefiguraciones políticas en tiempos inciertos. Tuxtla Gutiérrez, Chiapas: UNICACH.

Hermann, Andrés (2013) "El entramado sociotécnico en la construcción del conocimiento en la sociedad red". En Revista Sophia: Colección de Filosofía de la Educación, 15 Quito: Editorial Universitaria Abya-Yala.

Marcos, Sylvia (2014). "Feminismos en camino descolonial”. En Millán Márgara (coord.), Más allá del feminismo: caminos para andar. México: Red de Feminismos Descoloniales.

Paredes, Julieta (2013). Hilando fino. Desde el feminismo comunitario. México: El Rebozo, Zapateándole, Lente Flotante, En cortito que' s palargo, AliFem, A.C.

Segato, Rita (2016). La guerra contra las mujeres. Madrid: Traficantes de sueños. 